\section{Rare Case of Pheochromocytoma in a Young Female}

Sir,

Pheochromocytoma is the neuroendocrine tumor of adrenal medulla, which leads to excessive production of catecholamines mostly nor epinephrine. It is a rare tumor; and according to a study in United States, it only occurs in $0.5-0.8$ per 100,000 persons. ${ }^{1,2}$

Pheochromocytomas are associated with typical history of headache, sweating, and palpitations in episodic pattern. Around $98 \%$ of the cases are associated with hypertension; and half among them, gives history of intermittent hypertension. 3,4

Here, we report a young patient presenting with the typical history of pheochromocytoma.

A young female of 17 years presented at surgical clinic with history of episodic headache, sweating, palpitations, and vomiting for 8 months. Patient also gave history of weight loss. There was previous history of hypertension for one year. Familial history of hypertension was positive.

Clinical examination of the patient showed her to be a young girl with lean body mass and average height. At the time of headache, sweating and palpitation, her pulse rate was 100/min; blood pressure was 190/110 $\mathrm{mmHg}$, respiratory rate $18 / \mathrm{min}$; and patient remained afebrile during such episodes. Cardiovascular examination revealed displaced apex beat and audible $S 4$ on auscultation.

Her hemoglobin was $8.5 \mathrm{~g} / \mathrm{dl}$ and total leukocyte count (TLC) $6,100 / \mathrm{mm} 3$. Renal parameters, liver function tests and serum electrolytes were within normal limits. Vanillyl mandelic acid (VMA) level in 24-hour urine was $12.6 \mathrm{mg}$. CT scan abdomen with intravenous contrast revealed a well circumscribed heterogeneously enhancing soft tissue density mass lesion in left adrenal region causing anterior displacement of left renal vein as shown in Figure 1.

History, clinical examination, VMA level and imaging were consistent with the diagnosis of pheochromocytoma of left adrenal gland. Patient was put on phenoxybenzamine, b-blocker, and calcium channel blocker prior to surgery. Patient underwent elective laparotomy and left adrenalectomy. Her blood pressure remained $100 / 70 \mathrm{mmHg}$ during her postoperative stay in the ward and she did not complain of episodic headache and vomiting afterwards. At follow-up, one week later, her pulse rate was $76 / \mathrm{min}$, blood pressure $110 / 70 \mathrm{mmHg}$, respiratory rate $18 / \mathrm{min}$, and wound was healthy. Gross

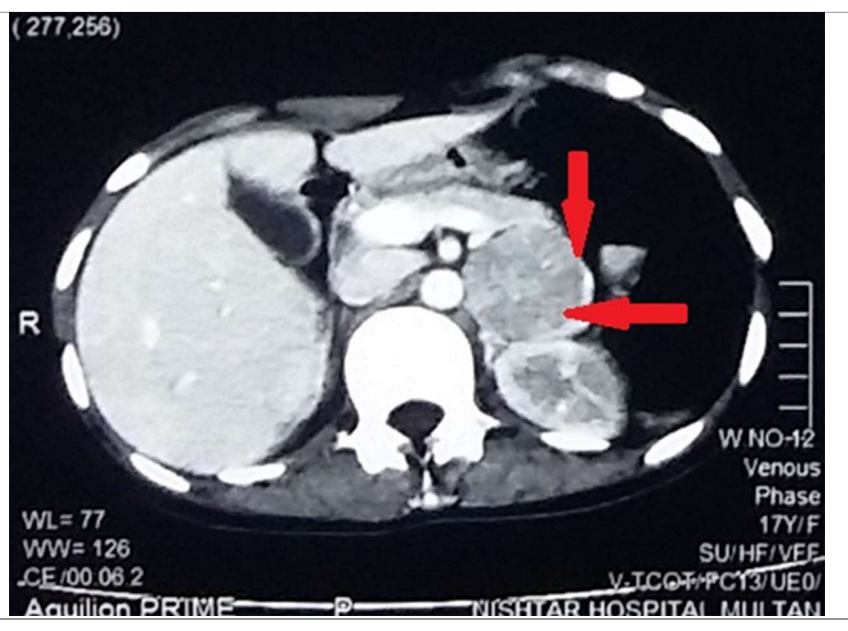

Figure 1: A well circumscribed heterogeneously enhancing soft tissue density mass lesion in left adrenal gland region causing anterior displacement of left renal vein.

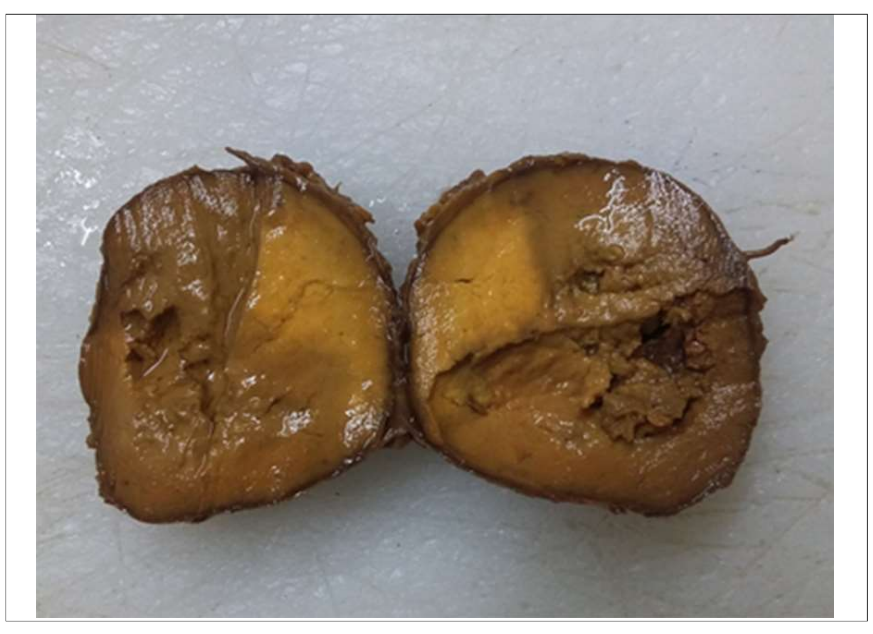

Figure 2: Adrenal gland tumor cut in two halves.

morphology of the specimen can be seen in Figure 2. Histopathology of the specimen revealed small nests of polygonal neuroendocrine cells with granular eosinophilic cytoplasm. The nuclei of the polygonal cells had typical "salt and pepper" chromatin, which was consistent with pheochromocytoma. There has always been a debate as to whether a strict management of blood pressure is obligatory or a more flexible approach is needed in preoperative plan. According to the recent Endocrine Society Clinical Guidelines recommendations, there should be addition of appropriate fluid therapy and salt intake along with alpha blockers in the preoperative period to avoid peroperative cardiac abnormalities. ${ }^{5}$ Laparoscopic resection is the preferred technique in most of the cases and in small tumors, while laparotomy and open resection is reserved for very large and malignant tumors. 5 It is said that $0.5 \%$ of patients diagnosed with hypertension have pheochromocytoma as the primary cause. 6 Patients of pheochromocytomas 
should also be screened for familial disorders such as von Hippel-Lindau (VHL) syndrome, multiple endocrine neoplasia type 2 (MEN2), and neurofibromatosis type 2 (NF2).

\section{REFERENCES}

1. Ariton M, Juan CS, AvRuskin TW. Pheochromocytoma: Clinical observations from a Brooklyn tertiary hospital. Endocr Pract 2000; 6:249-52

2. Guerrero MA, Schreinemakers JM, Vriens MR, Suh I, Hwang J, Shen WT, et al. Clinical spectrum of pheochromocytoma. J Am Coll Surg 2009; 209:727-32.

3. Juan D. Pheochromocytoma: Clinical manifestations and diagnostic tests. Urology 1981; 17:1-12.

4. James M. The impact of changes in drug availability for hemodynamic management in pheochromocytoma: Prêt-àporter or tailor-made? Can J Anaesth 2015; 62:1244-7.
5. Lenders JW, Duh QY, Eisenhofer G, Gimenez-Roqueplo AP, Grebe SK, Murad $\mathrm{MH}$, et al. Pheochromocytoma and paraganglioma: An endocrine society clinical practice guideline. J Clin Endocrinol Metab 2014; 99:1915-42.

6. Badui E, Mancilla R, Szymanski JJ, Garcia-Rubi D, Estañol B. Diverse clinical manifestations of pheochromocytomas. Angiology 1982; 33:173-82.

Mohammad Masood Ur Rauf Hiraj Khan' ${ }^{1}$, Junaid Zia Hashmi $^{1}$ and Ammarah Ghafoor ${ }^{2}$

Department of General Surgeryl / Internal Medicine ${ }^{2}$, Nishtar Hospital, Multan, Pakistan

Correspondence: Dr. Junaid Zia Hashmi, Department of General Surgery, Nishtar Hospital, Multan, Pakistan

E-mail: juneehashmi@yahoo.com

Received: August 28, 2018; Accepted: November 01, 2018 …諒.... 